\title{
Modifikasi Jembatan Mataraman II Malang Menggunakan Struktur Gelagar Beton Bertulang
}

\author{
Dita Kamarul Fitriyah ${ }^{1}$ \\ ${ }^{1}$ Jurusan Teknik Sipil, FTSP, Institut Adhi Tama Surabaya, Surabaya \\ E-mail: ditaka.fitriyah@gmail.com
}

\begin{abstract}
ABSTRAK: Jembatan Mataraman II yang terletak di Kabupaten Malang memiliki panjang \pm 40,8 $\mathrm{m}$ dengan lebar $\pm 11 \mathrm{~m}$. Jembatan ini semula didesain dengan standar bangunan atas tipe precast concrete I girder, metode girder precast, metode ini direkomendasikan pada jembatan Mataraman II, karena ekonomis, memperpendek waktu konstruksi dan workability. Jembatan eksisting ini didesain dengan tinggi I girder $1700 \mathrm{~mm}$ yang memiliki mutu beton precast concrete I girder K-500 ( $f^{\prime} c 415 \mathrm{~kg} / \mathrm{cm} 2$ ). Metode jembatan beton bertulang direkomendasikan pada jembatan ini, karena kriteria jembatan Mataraman II ini merupakan jembatan bentang pendek, sehingga jembatan beton bertulang cocok diterapkan dalam kasus ini. Selain itu juga, material yang digunakan memiliki sifat tahan lama, lebih ekonomis, dan mudah pemeliharaannya. Jembatan ini didesain dengan membangun abutment baru yang berjarak $\pm 2 \mathrm{~m}$ dari abutment lama dikarenakan agar tidak mengganggu lebar mulut sungai, sehingga panjang jembatan menjadi 44,80m. Dikarenakan panjang jembatan $>25 \mathrm{~m}$ maka kurang efektif dalam penggunaan gelagar beton bertulang, oleh karena itu direncanakan pilar yang berjarak $\pm 10 \mathrm{~m}$ dari rencana abutment baru. Perencanaan abutment direncanakan dengan didukung pondasi sumuran, dikarenakan pada kedalaman $4 \mathrm{~m}-5 \mathrm{~m}$ harga N-SPT didapatkan N > 50 ( tanah keras ).
\end{abstract}

KATA KUNCI : Beton Bertulang, Abutmen, Pilar, Pondasi Sumuran

\section{PENDAHULUAN}

Jembatan Mataraman II yang terletak di Kabupaten Malang perbatasan daerah Panggungwaru - Mataraman memiliki panjang bentang jembatan yaitu $\pm 40,8 \mathrm{~m}$ dengan lebar jembatan $\pm 11 \mathrm{~m}$. Jembatan Mataraman II ini, dalam kondisi eksisting didesain dengan standar bangunan atas tipe precast concrete I girder, yang merupakan metode girder precast. Desain tinggi profil precast concrete I girder mencapai $1700 \mathrm{~mm}$ dengan mutu beton precast concrete I girder yaitu K-500 atau setara $f^{\prime} c 415 \mathrm{~kg} / \mathrm{cm}^{2}$.

Dari data diatas, dapat disimpulkan bahwa, jembatan Mataraman II merupakan jembatan bentang pendek dan jika ditinjau berdasarkan kondisi daerah sekitarnya, akses untuk penggunaan alat berat akan sulit, karena jalan yang dilalui sempit. Sehingga tidak dimungkinkan untuk penggunaan girder precast, karena jalan yang sempit juga sulit dilalui alat alat berat untuk pengerjaan jembatan dengan gelagar precast I girder.

Pada kasus diatas, maka seorang perencanan perlu mempertimbangkan desain yang tepat agar material yang digunakan menjadi efisien dan efektif. Maka, pada metode ini, jembatan beton bertulang dipilih untuk alternatif pada kasus jembatan Mataraman II, karena dinilai ekonomis, memperpendek waktu konstruksi dan workability. Metode gelagar beton bertulang banyak digunakan pada beberapa macam jembatan bentang pendek dikarenakan tahan lama, mudah pemeliharaannya dan banyak menggunakan produk dalam negeri.

Kepala jembatan yang direncanakan didukung oleh pondasi sumuran, dikarenakan pada kedalaman $4 \mathrm{~m}-5 \mathrm{~m}$ nilai N-SPT pada pengujian tanah dengan Standart Penetration Test (SPT) telah mencapai $\mathrm{N}>50$, sebagai indikasi tanah keras.

\section{METODE PENELITIAN}

Adapun pada penelitian ini, metode yang digunakan dalam desain ulang jembatan Mataraman II sebagai berikut :
1) Tahap pengumpulan data

- Panjang jembatan : 40,8 m

- Lebar jembatan : $11 \mathrm{~m}$

- Elevasi MAT : $-3,113$

- Kedalaman sungai : $\pm 9,0 \mathrm{~m}$ (dari lantai kendaraan jembatan)

2) Preliminary desain

Desain jembatan beton bertulang direncanakan sebagai berikut yang terdapat pada Gambar 1:

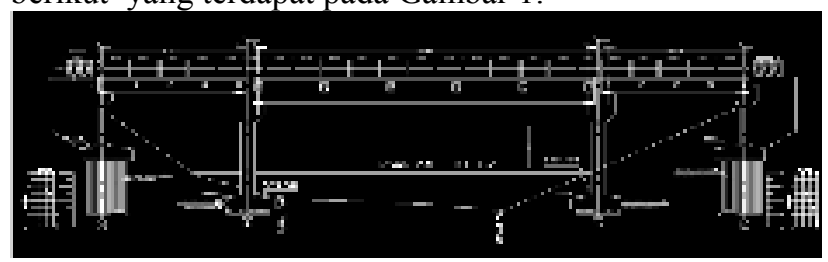

Gambar 1. Modifikasi Jembatan Mataraman II

Bentang jembatan Mataraman II (Gambar 1) menjadi 44,80 m, yaitu panjang bentang menjadi $10 \mathrm{~m}$ pada sisi kanan dan kiri, sedangkan pada tengah bentang jembatan menjadi $24,80 \mathrm{~m}$. Rencana diatas dimaksudkan agar pada bagian tengah bentang, mendapatkan bentang efektif pada jenis desain jembatan beton bertulang. Struktur utama yang digunakan adalah jembatan girder beton bertulang. Pada kedua sisi bentang tengah jembatan, didukung oleh pilar sejarak \pm 10 m dari rencana kepala jembatan (abutment) dengan posisi yang sudah dioptimalkan tidak mengganggu lebar mulut sungai. Pada modifikasi jembatan Mataraman II direncanakan menggunakan pondasi sumuran, yang merupakan salah satu jenis pondasi dangkal. Direncanakan pondasi sumuran berdiameter $3,0 \mathrm{~m}$, dengan kedalaman 4,0 m.

3) Permodelan Struktur

Pemodelan jembatan Mataraman II menggunakan bantuan program finite element (3 dimensi). 
4) Material yang digunakan

Jurnal Rekayasa Tenik Sipil Universitas Madura Vol. 4 No.1 Juni 2019 ISSN 2527-5542

a. Beton, berdasarkan Bridge Design Code tabel 6.3 hal 6-24 didapatkan bahwa perkerasan dan lantai jembatan yang berhubungan dengan lalu lintas menengah atau berat (kendaraan mempunyai masa kotor lebih dari 3 ton), kuat tekan karakteristik minimum untuk beton fc' adalah 28 MPa.

b. Baja tulangan, modulus elastisitas ( Ec ) berdasarkan SNI - 03-2847-2002 untuk beton normal dapat ditentukan dengan persamaan berikut :

$E_{\sigma}=4700 \sqrt{f_{\sigma}^{l}}$

Dimana :

$f^{\prime} c=$ merupakan kuat tekan silinder beton 28 hari yaitu sebesar 1,3.

c. Berdasarkan Tabel 1, tebal selimut beton direncanakan menurut keadaan lingkungan jembatan dan mutu beton yang digunakan, berdasarkan Bridge Design Code Tabel 6.6 halaman 6-28.

Tabel 1. Selimut nominal untuk auan dan kompaksi standar

\begin{tabular}{|c|c|c|c|c|c|}
\hline Klasifikasi & \multicolumn{4}{|c|}{$\begin{array}{c}\text { Selimut nominal (mm) } \\
\text { untuk beton dengan kuat } \\
\text { tekan }\left(\boldsymbol{f}^{\prime} \boldsymbol{c}\right) \text { tidak kurang } \\
\text { dari }-(\text { Mpa) }\end{array}$} \\
\hline Lingkungan & $\mathbf{2 0}$ & $\mathbf{2 5}$ & $\mathbf{3 0}$ & $\mathbf{3 5}$ & $\mathbf{4 0}$ \\
\hline A & 35 & 30 & 25 & 25 & 25 \\
\hline B1 & $(65)$ & 45 & 40 & 35 & 25 \\
\hline B2 & - & $(75)$ & 55 & 45 & 35 \\
\hline C & - & - & $(90)$ & 70 & 60 \\
\hline
\end{tabular}

d. Terkait dengan mutu baja tulangan, maka :

- Untuk tulangan dengan $\mathrm{D}<13 \mathrm{~mm}$, maka fsy $=280 \mathrm{MPa}$, Bridge Design Code, tabel 6.12 hal 35 .

- Untuk tulangan dengan $\mathrm{D} \geq 13 \mathrm{~mm}$, maka fsy $=400 \mathrm{MPa}$, Bridge Design Code, tabel 6.12 hal 35.

- Modulus elastisitas baja adalah 2.103 MPa, Bridge Design Code, tabel 6.12, pasal 2.2 hal 35.Apabila harga tegangan tidak lebih besar dari fsy.

5) Pembebanan pada jembatan

Pada perencanaan jembatan yang perlu diperhatikan adalah beban - beban yang terjadi pada jembatan. Beban - beban tersebut akan mempengaruhi besarnya dimensi dari struktur jembatan serta banyaknya tulangan yang diperlukan. Pada peraturan teknik jembatan Bridge Management System 1992 aksi-aksi ( beban ) digolongkan berdasarkan sumbernya yaitu :

- Beban Mati

Beban mati struktur jembatan adalah berat sendiri dari masing - masing bagian struktural jembatan dan berat mati tambahan yang berupa berat perkerasan. Masing - masing berat bagian tersebut harus dianggap sebagai aksi yang saling terkait.

- Beban Hidup

Beban hidup jembatan meliputi :

- Beban lalu lintas
Beban lalu - lintas untuk perencanaan struktur jembatan terdiri dari beban lajur " $\mathrm{D}$ " dan beban truk " $\mathrm{T}$ ":

- Beban Lajur "D"

Pada Gambar 2 dan Gambar 3, dijelaskan bahwa beban lajur D bekerja pada seluruh lebar jalur kendaraan dan menimbulkan pengaruh pada girder yang ekivalen dengan suatu iring - iringan kendaraan yang sebenarnya. Intensitas beban D terdiri dari beban tersebar merata dan beban garis.

Beban Tersebar Merata $(\mathrm{UDL}=\mathrm{q})$. Dengan q tergantung pada panjang yang dibebani total (L). jika $\mathrm{L}<30 \mathrm{~m}, \mathrm{q}=8,0 \mathrm{kN} / \mathrm{m}^{2}$, sebaliknya apabila $\mathrm{L} \geq 30 \mathrm{~m}, \mathrm{q}=8,0(0,5+$ $15 / \mathrm{L}) \mathrm{kM} / \mathrm{m}^{2}$.

Beban Garis $(\mathrm{KEL}=\mathrm{P})$, ditetapkan sebesar 44 $\mathrm{kN} / \mathrm{m}$.
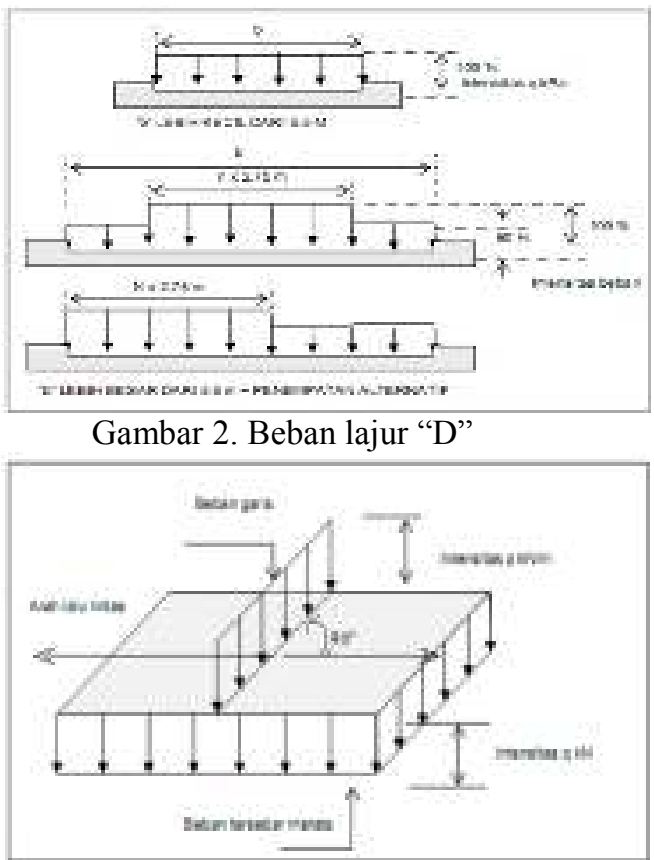

Gambar 3. Kedudukan beban lajur "D"

- Beban truk

Beban truk "T" adalah kendaraan berat tunggal dengan 3 as (Gambar 4) yang ditempatkan dalam pada beberapa posisi yang digunakan untuk menganalisis pelat pada lajur lalu lintas rencana. Tiap gandar terdiri dari dua pembebanan bidang kontak yang dimaksud agar mewakili pengaruh roda kendaraan berat. Hanya satu truk " $T$ " boleh ditempatkan per lajur lalu lintas rencana. Beban

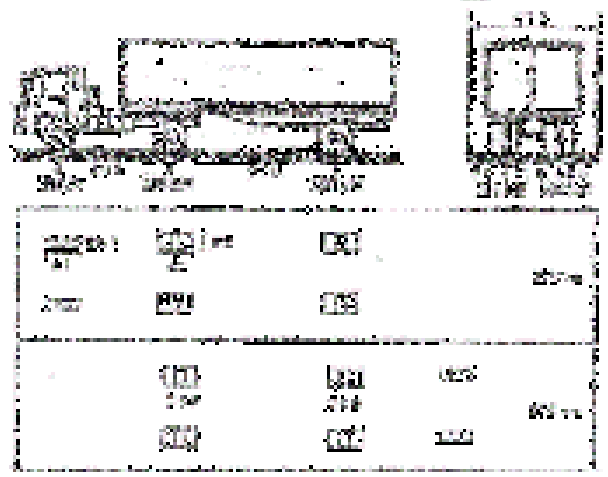


Analisa kebutuhan penulangan pada struktur beton

Gambar 4. Pembebanan truk

- Faktor Pembesaran Dinamis

Faktor pembesaran dinamis (DLA) berlaku pada "KEL" lajur "D" dan truk "T" sebagai simulasi kejut dari kendaraan bergerak pada struktur jembatan. Untuk Truk "T" nilai DLA adalah 0,30 sedangkan untuk "KEL" lajur "D" nilai dapat dilihat Tabel 2 dibawah ini.

Tabel 2. Faktor Beban Dinamik untuk "KEL" Lajur "D"

\begin{tabular}{|c|c|}
\hline Bentang Ekuivalen $\mathbf{L}_{\mathbf{E}}$ & $\begin{array}{c}\text { DLA } \\
\text { (Untuk kedua keadaan } \\
\text { batas) }\end{array}$ \\
\hline $\mathbf{L}_{\mathbf{E}} \leq \mathbf{5 0}$ & 0,04 \\
\hline $\mathbf{5 0} \leq \mathbf{L}_{\mathbf{E}} \leq \mathbf{9 0}$ & $0,525-0,0025 \mathrm{LE}$ \\
\hline $\mathbf{L}_{\mathbf{E}} \geq \mathbf{9 0}$ & 0,30 \\
\hline
\end{tabular}

- Gaya Rem

Pengaruh pengereman kendaraan diperhitungkan dalam analisis jembatan dimana gaya tersebut bekerja pada permukaan lantai jembatan. Pengaruh gaya rem dan percepatan lalu - lintas harus dipertimbangkan sebagai gaya memanjang. Gaya ini tidak tergantung pada lebar jembatan dan diberikan dalam Tabel 3 untuk panjang struktur yang tertahan.

Tabel 3. Gaya Rem

\begin{tabular}{|c|c|}
\hline $\begin{array}{c}\text { Panjang Struktur } \\
(\mathbf{m})\end{array}$ & $\begin{array}{c}\text { Gaya Rem SLS } \\
(\mathbf{k N})\end{array}$ \\
\hline $\mathbf{L} \leq \mathbf{8 0}$ & 250 \\
\hline $\mathbf{8 0}<\mathbf{L} \leq \mathbf{9 0}$ & $2,5 \mathrm{~L}+50$ \\
\hline $\mathbf{L}_{\mathbf{E}} \geq \mathbf{1 8 0}$ & 500 \\
\hline Catatan : Gaya rem ULS adalah 2,0 gaya rem SLS \\
\hline
\end{tabular}

- Beban Gempa

Pembebanan gempa dilakukan dengan analisa numerik beban dinamis dengan metode respon spektrum.

- Maka didapatjkan pembebanan struktur yaitu sebagai berikut beserta Gambar 5 :

- $\quad$ Beban mati $=121 \mathrm{kN}$

- $\quad$ Beban hidup $=158,8 \mathrm{kN}$

- Beban rem $=250 \mathrm{kN}$

- Beban gempa (Respon Spektrum)

Ss $=0,565$

$\mathrm{S}_{1}=0,296$

$\mathrm{T}_{0}=0,105$ detik

$\mathrm{T}_{\mathrm{s}}=0,523$ detik

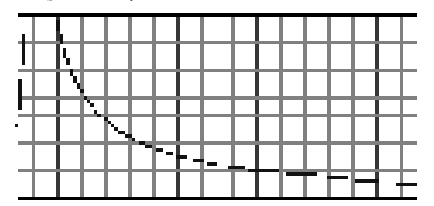

Gambar 5. Respon Spektrum Kota Malang

Adapun kombinasi pembebanan yang digunakan yaitu sebagai berikut :

1. 1,3 DL + 1,8 LL

2. $1.3 \mathrm{DL}+1,8 \mathrm{R}+1,8 \mathrm{~T}$

3. $1,3 \mathrm{DL}+1,4 \mathrm{~W}$

4. 1,0 DL + 0,3 LL + 1,0 EX

5. 1,0 DL + 0,3 LL + 1,0 EY

6) Analisa Kebutuhan Tulangan berdasarkan pada SNI 2013.

7) Kontrol Pondasi

Nilai minimum dari SF (Safety Factor) terhadap geser dan guling yang digunakan dalam perencanaan adalah masing masing 1,50. (Onding dkk : 2013)

\section{HASIL PENELITIAN}

1) Pemodelan struktur

Pemodelan struktur dilakukan dengan program bantu finite element dapat dilihat pada Gambar 6.

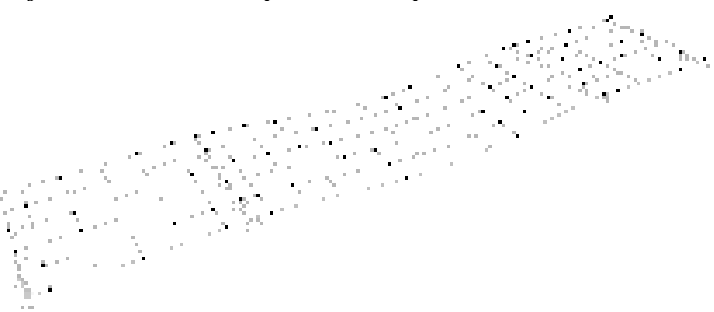

Gambar 6. Pemodelan Struktur dengan Finite Element

2) Perencanaan Pelat Lantai

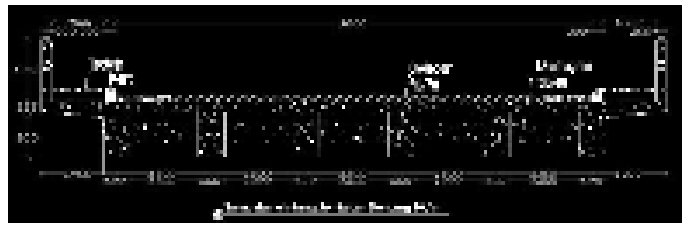

Gambar 7. Tampak Melintang Jembatan

Berdasarkan BMS 1992, ditentukan bahwa perencanaan tebal pelat lantai kendaraan pada jembatan yaitu sebagai berikut :

$200 \leq \mathrm{D} \geq 100+0,04 \mathrm{~L}$

Dari perhitungan diatas, didapatkan tebal perkerasan adalah $225 \mathrm{~mm}$.

- Kontrol tebal pelat rencana terhadap geser ponds. - Posisi roda



Gambar 8. Beban roda berada pada tengah pelat

Mengacu pada Gambar 8, dimana Vuc (ijin) > Vuc (ult), maka didapatkan sebagai berikut :

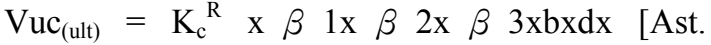
$($ fc'/(b.d $))]^{1 / 3}$

$$
\begin{gathered}
=138,188 \mathrm{kN} \\
\operatorname{Vuc}_{(\mathrm{ijin})}=0,6 \times(1 / 6) \mathrm{x}\left(\mathrm{fc}^{\prime}\right) 1 / 2 \mathrm{x} \mathrm{b} \times \mathrm{d} \\
=266,193 \mathrm{kN}
\end{gathered}
$$

Maka dapat disimpulkan bahwa, tebal pelat yang direncanakan mampu menerima geser ponds yang terjadi.

- Data Penulangan Pelat lantai kendaraan

Tebal pelat lantai $=225 \mathrm{~mm}$ 


$$
\begin{array}{ll}
f^{\prime} c \text { (Mutu beton) } & =30 \mathrm{MPa} \\
f y \text { (Mutu baja) } & =390 \mathrm{MPa} \\
\text { Decking } & =40 \mathrm{~mm} \\
\varnothing \text { tulangan } & =19 \mathrm{~mm} \text { (melintang) } \\
\varnothing \text { tulangan } & =10 \mathrm{~mm} \text { (memanjang) }
\end{array}
$$

- Penulangan Pelat lantai kendaraan

Tulangan melintang D19 - 200

$\left(\right.$ As $\left.=1417,64 \mathrm{~mm}^{2}\right)$

Tulangan memanjang D10 - 125

$\left(\right.$ As $\left.=628,32 \mathrm{~mm}^{2}\right)$

3) Diafragma

Direncanakan dimensi diafragma 300 x $500 \mathrm{~mm}$.

- Data Penulangan Diafragma

$$
\begin{array}{ll}
f^{\prime} c \text { (Mutu beton) } & =35 \mathrm{MPa} \\
f y \text { (Mutu baja) } & =390 \mathrm{MPa} \\
\text { Decking } & =40 \mathrm{~mm} \\
\varnothing \text { tulangan } & =19 \mathrm{~mm} \text { (lentur) } \\
\varnothing \text { tulangan } & =10 \mathrm{~mm} \text { (geser) }
\end{array}
$$

- Besar gaya dalam yang terjadi

Tabel 4. Gaya dalam pada diafragma

\begin{tabular}{|c|c|c|c|c|c|}
\hline $\mathbf{P}$ & $\mathbf{V 2}$ & $\mathbf{V 3}$ & $\mathbf{T}$ & $\mathbf{M} 2$ & $\mathbf{M 3}$ \\
\hline $\mathbf{k N}$ & $\mathbf{k N}$ & $\mathbf{k N}$ & $\mathbf{k N}-\mathbf{m}$ & $\mathbf{k N}-\mathbf{m}$ & $\mathbf{k N}-\mathbf{m}$ \\
\hline $\mathbf{3 . 5 8 1}$ & 104.004 & 1.38 & 6.691 & 1.243 & 60.600 \\
\hline $\mathbf{- 3 . 5 8 1}$ & 104.004 & -1.38 & -6.691 & -1.243 & -41.695 \\
\hline
\end{tabular}

Tabel 4 merupakan gaya dalam yang terjadi pada struktur diafragma, yang selanjutnya digunakan dalam analisa penulangan diafgarma. Maka didapatkan hasil sebagai berikut :

- Penulangan Diafragma

Tulangan lentur tumpuan 11 D19

$\left(\right.$ As $\left.=3001,55 \mathrm{~mm}^{2}\right)$

Tulangan lentur lapangan 6 D19

$\left(\right.$ As $\left.=1573,65 \mathrm{~mm}^{2}\right)$

Tulangan geser tumpuan 2 D10 - 100

$\left(\right.$ As $\left.=1570,80 \mathrm{~mm}^{2}\right)$

Tulangan geser lapangan 2 D10 - 150

$\left(\right.$ As $\left.=1047,20 \mathrm{~mm}^{2}\right)$

4) Girder

Direncanakan dimensi girder 500 x $800 \mathrm{~mm}$.

- Data Penulangan Girder

$$
\begin{array}{ll}
f^{\prime} c \text { (Mutu beton) } & =30 \mathrm{MPa} \\
f y \text { (Mutu baja) } & =390 \mathrm{MPa} \\
\text { Decking } & =40 \mathrm{~mm} \\
\varnothing \text { tulangan } & =19 \mathrm{~mm} \text { (lentur) } \\
\varnothing \text { tulangan } & =10 \mathrm{~mm} \text { (geser) }
\end{array}
$$

- Besar gaya dalam yang terjadi

Tabel 5. Gaya dalam pada girder

\begin{tabular}{|c|c|c|c|c|c|}
\hline $\mathbf{P}$ & $\mathbf{V 2}$ & $\mathbf{V 3}$ & $\mathbf{T}$ & $\mathbf{M} 2$ & $\mathbf{M 3}$ \\
\hline $\mathbf{k N}$ & $\mathbf{k N}$ & $\mathbf{k N}$ & $\mathbf{k N}-\mathbf{m}$ & $\mathbf{k N}-\mathbf{m}$ & $\mathbf{k N}-\mathbf{m}$ \\
\hline $\mathbf{2 3 . 9 1}$ & 106.05 & 2.92 & 11.26 & 21.21 & 702.2 \\
\hline $\mathbf{- 2 3 . 9 1}$ & -106.05 & -2.92 & -11.26 & -21.21 & -702.2 \\
\hline
\end{tabular}

Tabel 5 merupakan gaya dalam yang terjadi pada struktur girder, yang selanjutnya digunakan dalam analisa penulangan girder. Maka didapatkan hasil sebagai berikut :

- Penulangan Girder

Tulangan lentur tumpuan 12 D19

$\left(\right.$ As $\left.=3258,73 \mathrm{~mm}^{2}\right)$

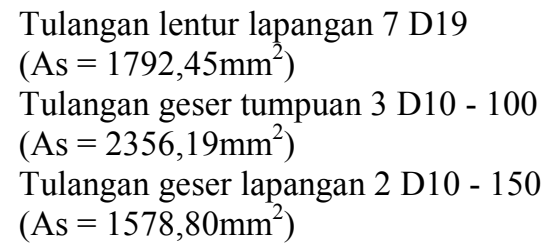

5) Perletakan

Perletakan yang digunakan dalam perencanaan ini yaitu tipe bearing pad fabrikasi.



Gambar 9. Rubber Bearing Pad

- Gaya yang bekerja pada perletakan

Tabel 6. Gaya yang bekerja pada perletakan

\begin{tabular}{|l|c|c|c|}
\multicolumn{1}{c|}{ Gaya } & $\mathbf{V ~ ( k N )}$ & $\mathbf{H x}(\mathbf{k N})$ & Hy (kN) \\
\hline Gaya vertikal & 1391,11 & & \\
\hline Gaya gesek & & 1804,61 & \\
Gaya Rem & & 41,67 & \\
\hline Gaya Gempa & & 151,59 & 151,59 \\
\hline Total & $\mathbf{1 3 9 1 , 1 1}$ & $\mathbf{1 9 9 7 , 8 7}$ & $\mathbf{1 5 1 , 5 9}$ \\
\hline
\end{tabular}

Tabel 6 menunjukkan besaran gaya yang terjadi pada perletakan. Gaya tersebut digunakan dalam beberapa point kontrol perletakan, untuk menentukan dimensi perletakan yang akan digunakan.

- Kontrol perletakan

Berdasarkan BMS 1997 dilakukan kontrol perletakan bearing pad sebagai berikut :

1. Kontrol luas efektif minimum

$$
\begin{array}{ll}
\text { Aeff/0,8 A } & \geq 1,00 \\
1,24 & \geq 1,00 \quad(\mathrm{OK})
\end{array}
$$

2. Kontrol; regangan total maksimum

$$
\begin{array}{ll}
\varepsilon \mathrm{T}=\varepsilon \mathrm{Sc}+\varepsilon \mathrm{Sr}+\varepsilon \mathrm{Sh} & \leq 2,6(\mathrm{G})^{0,5} \\
2,54 & \leq 3,13 \quad(\mathrm{OK})
\end{array}
$$

3. Kontrol regangan geser maksimum

$$
\begin{array}{ll}
\varepsilon S h(\max ) / \varepsilon S h & \geq 1,00 \\
24,45 & \geq 1,00 \quad(\mathrm{OK}) \\
\text { 4. Kontrol batas leleh } & \\
1,4 \mathrm{~V} / \varepsilon S c \mathrm{~V}_{\mathrm{LL}} & \geq 1,00 \\
3,39 & \geq 1,00 \quad(\mathrm{OK})
\end{array}
$$

5. Kontrol; tegangan maksimum rata rata

$$
\begin{array}{ll}
0,015 \mathrm{At} / \mathrm{V} & \geq 1,00 \\
1,24 & \geq 1,00 \quad(\mathrm{OK})
\end{array}
$$

6. Kontrol perputaran maksimum

$$
\begin{array}{ll}
\alpha / 4 \mathrm{dc} & \geq 1,00 \\
439,41 & \geq 1,00 \quad(\mathrm{OK})
\end{array}
$$

7. Kontrol stabilitas tekan

$$
\begin{array}{ll}
2 \text { be G S Aeff / 1000/V } & \geq 1,00 \\
510,363 & \geq 1,00
\end{array}
$$

8. Kontrol tebal baja minimum ts $/ 3$
$\geq 1,00$
1,67
$\geq 1,00 \quad(\mathrm{OK})$
9. Kontrol tahan gesek terhadap geser

$$
\begin{array}{ll}
0,1 \mathrm{~V}+300 \mathrm{Aeff} / \mathrm{H} & \geq 1,00 \\
215,19 & \geq 1,00 \quad(\mathrm{OK})
\end{array}
$$


Dari kontrol diatas, dapat disimpulkan bahwa digunakan dimensi perletakan yaitu 340 x 320 x 51 dengan spesifikasi sebagai berikut :

Tebal karet $\quad=12 \mathrm{~mm}$

Tinggi perletakan $=51 \mathrm{~mm}$

Tebal pelat baja $=5 \mathrm{~mm}$

Tebal selimut sisi $=10 \mathrm{~mm}$

6) Abutment

Kontrol abutmen dilakukan terhadap geser dan guling dasar pondasi, yaitu sebagai berikut :

$$
\mathrm{SF}=3,28 \quad \geq 1,5 \quad(\mathrm{OK})
$$

7) Pondasi

Pada pondasi sumuran dilakukan kontrol terhadap tegangan tanah dan geser pondasi yaitu :

- Kontrol tegangan tanah Qijin $=41,671 \mathrm{Tm}^{-2}>$ Qult $=28,36 \mathrm{Tm}^{-2}(\mathrm{OK})$

- Kontrol geser pondasi Vult $=200,46 \mathrm{~T}<$ Vijin $=347,48(\mathrm{OK})$

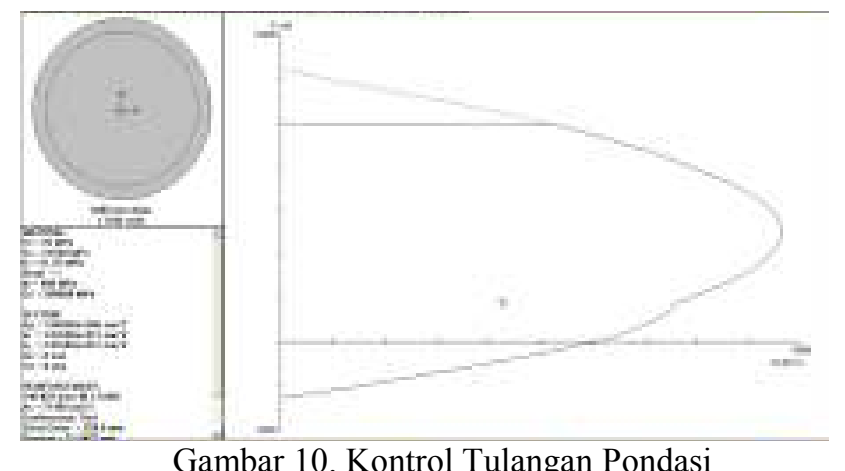

Gambar 10. Kontrol Tulangan Pondasi

Dari pemeriksaan dengan PCACOL (Gambar 10) didapatkan penulangan yang memenuhi yaitu sebanyak 140 D 25 dengan rasio sebesar 1,01\%.

\section{KESIMPULAN}

Dari hasil modifikasi diatas didapatkan kesimpulan yaitu sebagai berikut.

1) Bentang jembatan Mataraman II menjadi $44,80 \mathrm{~m}$, yaitu panjang bentang menjadi $10 \mathrm{~m}$ pada sisi kanan dan kiri, sedangkan pada tengah bentang jembatan menjadi 24,80 m.

2) Penambahan abutmen pada jembatan.

3) Lantai kendaraan didapatkan yaitu $225 \mathrm{~mm}$, dengan f'c 30 Mpa. Penulangan pada pelat lantai kendaraan yaitu D19 - 200 (melintang) dan D10 - 125 (memanjang).

4) Dimensi diafragma $300 \times 500 \mathrm{~mm}$, dengan f'c 30 Mpa. Didapatkan tulangan lentur tumpuan 11 D19, tulangan lentur lapangan $6 \mathrm{D} 19$, tulangan geser tumpuan 2 D10 - 100, dan tulangan geser lapangan 2 D10 - 150 .

5) Dimensi girder 500 x $800 \mathrm{~mm}$, dengan f'c $30 \mathrm{Mpa}$. Didapatkan Tulangan lentur tumpuan 12 D19, tulangan lentur lapangan $7 \mathrm{D} 19$, tulangan geser tumpuan 3 D10 - 100, dan tulangan geser lapangan 2 D10 - 150

6) Dimensi perletakan didapatkan yaitu $340 \times 320 \times 51$ $\mathrm{mm}$.
7) Pondasi sumuran berdiameter 3,0 m, dengan kedalaman 4,0 m.

8) Abutmen dan pondasi yang didesain pada jembatan ini mampu untuk menahan beban layan yang terjadi.

\section{DAFTAR PUSTAKA}

Onding, Julfrenly \& Sjachrul, Balamba \& Sompie, Berty \& Sarajar, A.N. (2013). Analisis Kestabilan Pondasi Jembatan Strudi Kasus : Jembatan Essang-Lalue. Sam Ratulangi University.

Bridge Management System (BMS). (1992). Peraturan Perencanaan Teknik Jembatan (Bridge Design Code). Departemen Pekerjaan Umum, Direktorat Jenderal Bina Marga, Direktorat Bina Program Jalan. Jakarta.

Supriyadi, B. Muntohar, A.S. (2000). Jembatan (edisi pertama). Jurusan Teknik Sipil Universitas Gadjah Mada. Yogyakarta.

Hardiyatmo, Hary Christady., (2015). Analisis dan Perancangan Fondasi I, Penerbit Gadjah Mada University Pres, Edisi ke-tiga, Yogyakarta.

Das, B. M., (1995). Mekanika Tanah I (Prinsip-prinsip Rekayasa Geoteknis), Penerbit Erlangga, Jakarta. 
Jurnal Rekayasa Tenik Sipil Universitas Madura Vol. 4 No.1 Juni 2019 ISSN 2527-5542

Halaman Ini Sengaja Dikosongkan 